Revista Tecné, Episteme y Didaxis: TED. Año 2014, Número Extraordinario. ISSN Impreso: 0121-3814, ISSN web: 2323-0126

Memorias, Sexto Congreso Internacional sobre Formación de Profesores de Ciencias. 08 al 10 de octubre de 2014, Bogotá

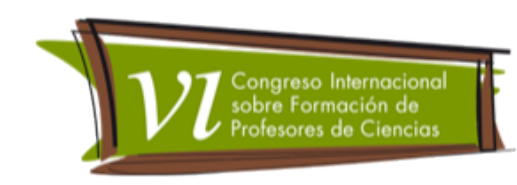

\title{
Propuesta de un Diseño Curricular desde las Cuestiones Sociocientíficas
}

Castro González, Pedro Andrés y y Carrión Pérez, Diana Catalina²

Categoría 2. Trabajo de investigación

\section{Resumen}

En la presente comunicación se resalta la construcción de una propuesta enmarcada en el proyecto "Programa Colombo-Brasileño de Formación de Profesores de Ciencias en la Interfaz Universidad-Escuela Col-Upn-531-12" para la elaboración de un diseño curricular desde el abordaje de las Cuestiones SocioCientíficas, el cual posibilita la construcción de un currículo centrado en la integración de diferentes conocimientos pedagógicos-didácticos y disciplinares y apoyará a que durante el proceso los sujetos se puedan formar con ética y valores como agentes activos, políticos y sociales. La investigación se pretende desarrollar en dos instituciones educativas del sector privado de la ciudad de Bogotá (Colombia), con los grados $4^{\circ}$ y $5^{\circ}$ (Institución educativa A) y $6^{\circ}$ y $7^{\circ}$ (institución educativa B).

\section{Palabras clave}

Cuestión sociocientífica, Cuestión socioambiental, diseño curricular, microcurrículo.

\section{Objetivos}

Para la investigación en desarrollo, se tiene como objetivo "Caracterizar el microcurrículo de ciencias naturales de dos instituciones educativas y a partir de ello, diseñar una propuesta desde la perspectiva de las Cuestiones Sociocientíficas o Socioambientales" que favorezca la comprensión de problemáticas globales-locales en el estudiantado, para lo cual se plantea:

- Analizar el microcurrículo de ciencias naturales de dos instituciones educativas de carácter privado de la ciudad de Bogotá.

1 Liceo Campo David. pecastro22@hotmail.com

2 Candidata a magister, Universidad Pedagógica nacional. dianacarrioncp@gmail.com Temática 1. Enfoque CTS: Alfabetización científica y Cuestiones socio científicas 
Revista Tecné, Episteme y Didaxis: TED. Año 2014, Número Extraordinario. ISSN Impreso: 0121-3814, ISSN web: 2323-0126

Memorias, Sexto Congreso Internacional sobre Formación de Profesores de Ciencias. 08 al 10 de octubre de 2014, Bogotá

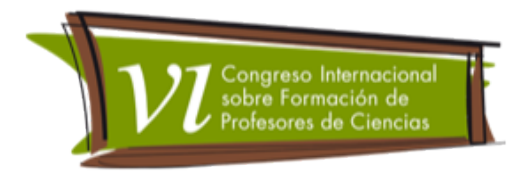

- Identificar y analizar los principios que desde las Cuestiones Sociocientíficas o Socioambientales permiten desarrollar una propuesta curricular acorde con las problemáticas globales-locales seleccionadas.

- Diseñar y evaluar un microcurrículo desde la perspectiva de Cuestiones Sociocientíficas o Socioambientales, que permita abordar problemáticas globales-locales.

\section{Marco teórico}

Uno de los desafíos de la educación en ciencias es, superar la imagen y actitud negativa generada en el aula de clase y la forma como éstas influencian los diseños curriculares propuestos, por lo tanto, es necesario analizar los currículos en ciencias, pues conforman creencias, actitudes y valores que desarrollan el interés crítico en la actividad científica, destacando que en los últimos años se viene reclamando insistentemente una educación científica y tecnológica con características más humanistas, pero vale la pena analizar cómo ha sido la influencia de esos diseños curriculares en el desarrollo de la educación científica .

Según Martínez (2012), en las aulas de clase prima la teoría tecnicista de currículo tradicional, por lo cual al implementar un currículo basado en Ciencia, Tecnología y Sociedad (CTS) se permite realizar un análisis crítico a estas propuestas, enfatizando en el discurso de los docentes y logrando que por medio de la implementación de las CSC se favorezca el proceso de enseñanza, posibilitando entender que el currículo no puede ser reducido a los contenidos específicos de ciencia.

La construcción del currículo en la práctica permite la investigación e innovación educativa (Snyder et al., 1992, citado en Membiela, 2002), como un conjunto de experiencias creadas por estudiantes y profesores, quienes adquieren un papel clave por su participación en la creación de conocimiento en la práctica o en el cambio curricular, entendido éste como un proceso de desarrollo individual y cambio en el pensamiento y práctica de profesores y estudiantes.

En el contexto colombiano, según la ley general de educación, el currículo es el conjunto de criterios, planes de estudio, programas, metodologías, y procesos que contribuyen a la formación integral y a la construcción de la identidad cultural nacional, regional y local, incluyendo también los recursos humanos, académicos y físicos para poner en práctica las políticas y llevar a cabo el proyecto educativo institucional (artículo 76), promoviendo así algunos de los fines de la educación como 
Revista Tecné, Episteme y Didaxis: TED. Año 2014, Número Extraordinario. ISSN Impreso: 0121-3814, ISSN web: 2323-0126

Memorias, Sexto Congreso Internacional sobre Formación de Profesores de Ciencias. 08 al 10 de octubre de 2014, Bogotá

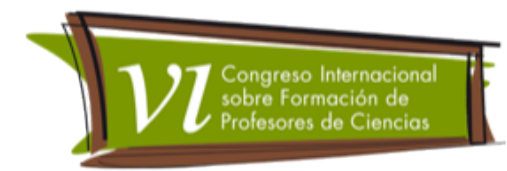

la adquisición y generación de los conocimientos científicos y técnicos más avanzados mediante la apropiación de hábitos intelectuales adecuados para el desarrollo del saber.

Las cuestiones sociocientíficas son consideradas como una propuesta para la enseñanza de las ciencias desde la interacción entre Ciencia, Tecnología, Sociedad y Ambiente (CTSA) que se generan en el salón de clases aportando a su vez a la formación del profesor investigador y al fortalecimiento de su autonomía, logrando la apertura de un camino concreto en la enseñanza de las ciencias para conquistar los retos propuestos por la educación CTSA. De esta forma, resulta importante para la formación ciudadana de los estudiantes, comprender la ciencia como una actividad humana que presenta múltiples controversias e incertidumbres en su constitución y por tanto, requería de alcances e impactos. La constitución de una ciudadanía democrática con énfasis en temas polémicos relacionados con ciencia y tecnología, requiere la participación real de los ciudadanos en la toma de decisiones (Martínez et al, 2012).

En el cambio de las sociedades en busca de respuestas, el docente debe dejar la idea de "dar", de orientar solamente su disciplina, se debe generar un compromiso con la construcción de sociedades democráticas dentro del aula de clase, para que los educandos logren practicar críticamente en la sociedad, por lo cual es necesario que la Enseñanza de las Ciencias sea vista como una preocupación constante para formar sujetos críticos que participen en controversias sociocientíficas, por medio de la vivencia de experiencias formativas (Martínez et al, 2012).

El abordaje de las Cuestiones Sociocientíficas es de gran atención en la experiencia cotidiana por medio del cumplimiento de las siguientes características según Ratccliffe (2009):

- Tener una base científica

- Involucrar la formación de opiniones

- Puede abordar las dimensiones locales, nacionales y globales

- Involucrar los valores y el razonamiento ético

- Puede requerir comprensión de probabilidad y riesgo

Según Torres (2011), dentro de los objetivos de la CSC se encuentran: 
Revista Tecné, Episteme y Didaxis: TED. Año 2014, Número Extraordinario. ISSN Impreso: 0121-3814, ISSN web: 2323-0126

Memorias, Sexto Congreso Internacional sobre Formación de Profesores de Ciencias. 08 al 10 de octubre de 2014, Bogotá

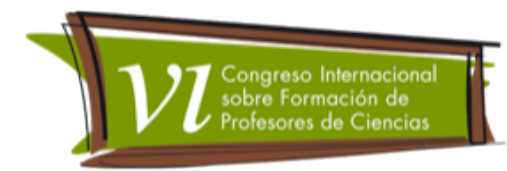

- El estudiante logra actuar en la sociedad con responsabilidad social y de este modo tomar decisiones frente a las problemáticas que se presentan en su cotidianidad.

- Permiten la participación ciudadana en la toma de decisiones.

- Fortalecen al ser humano en su capacidad de reflexión y crítica.

- Relacionan los asuntos científicos y tecnológicos con la sociedad.

- Generan controversias dentro de la sociedad creando un espíritu de crítica frente a las problemáticas y temáticas y desarrollo del mundo en el contexto de la ciencia, la tecnología y la sociedad.

\section{Metodología}

Se realizará una investigación acción, la cual ha surgido principalmente desde la educación popular, a través de la producción y uso del conocimiento en sectores con situación de vulnerabilidad, procurando de este modo el cambio social y político para el progreso, de igual modo la investigación acción (IA) no constituye el fin último de la investigación, sino que más bien se ve como un medio para orientar la planeación de la acción social organizada, que se encauza a la transformación de algún tipo de realidad social que resulta insatisfactoria al grupo humano involucrado en el proceso investigativo (Membiela, 2002).

Membiela (2002), menciona que la investigación acción (IA) está interesada en los problemas prácticos que encuentran los profesores en las aulas y encontrar soluciones a estos, estableciendo la idea de los profesores como investigadores para incorporar la teoría crítica en el análisis de las condiciones existentes en las escuelas, dentro de los beneficios de trabajar con una metodología de IA, encontramos:

- Añade la teoría y el conocimiento base que los profesores necesitan para mejorar su práctica de enseñanza.

- Hace a los profesores interesados y conscientes de los hallazgos de la investigación, porque se desarrolla en la escuela un clima de indagación y mejora sistemática.

- Se crea un clima de colaboración entre todos los participantes para la mejora educativa.

- Ayuda a identificar problemas y buscar soluciones de manera sistemática.

- Base de los programas de formación permanente en las escuelas, que promueven mejoras prácticas y el posterior desarrollo de los profesores. 
Revista Tecné, Episteme y Didaxis: TED. Año 2014, Número Extraordinario. ISSN Impreso: 0121-3814, ISSN web: 2323-0126

Memorias, Sexto Congreso Internacional sobre Formación de Profesores de Ciencias. 08 al 10 de octubre de 2014, Bogotá

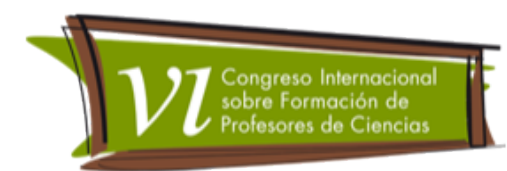

La presente investigación se pretende realizar en dos instituciones educativas, del sector privado de la Ciudad de Bogotá, Colombia, trabajando en cada una de ellas poblaciones distintas, pero intentando la integración y consecución de los diseños curriculares, debido a que la institución educativa $A$ trabaja educación básica hasta el ciclo $2\left(4^{\circ}\right.$ y $\left.5^{\circ}\right)$ y en la institucion B se trabajara el ciclo $3\left(6^{\circ}\right.$ y 7$)$ teniendo como base la integracion curricular que se debe mantener entre las instituciones de educacion formal.

La elección de los grados se hace teniendo en cuenta la organización educativa dada por el ministerio de educacion nacional de Colombia donde se trabajan los ciclos educativos, al trabajar dos ciclos seguidos permitirá dar continuidad a las temática seleccionadas y facilita la incorporación de cada uno de los estándares del área.

La investigación se realizará dentro de la IA, pues los docentes participantes son docentes en ejercicio de las instituciones educativas, por lo tanto los microcurrículos a diseñar, serán planteados a partir de la investigación y desarrollo de la propuesta dentro del aula de clase, como lo menciona Stenhouse (1981), no se requiere solamente el estudio de la labor de los profesores, para que se genere cambio en el currículo, es necesario que se estudien ellos mismos. Desarrollar la investigación dentro de la IA, permitirá que los docentes mediten profundamente acerca de sus métodos y técnicas y evaluar sus propios rendimientos (Cooper y Ebbutt, 1974 citado en Stenhouse, 1981).

\section{Fases de la investigación}

- Fase de Diagnóstico

En esta fase se realiza un análisis de las mallas curriculares propuestas en las instituciones a trabajar y desde este análisis se determina la importancia de reestructurar el diseño curricular.

Se describen las problemáticas que dan origen a la necesidad de modificar el currículo, entrevistar a los profesores sobre el currículo, a los estudiantes, y directivas acerca de intereses en la clase de ciencias, las actividades, la forma de evaluación, y demás componentes del currículo, además de actividades como lluvia de ideas, trabajos escritos, reflexiones o encuestas con los estudiantes para determinar las cuestiones socio científicas o socio ambientales para construir el diseño curricular.

- Fase de Diseño, implementación y evaluación 
Revista Tecné, Episteme y Didaxis: TED. Año 2014, Número Extraordinario. ISSN Impreso: 0121-3814, ISSN web: 2323-0126

Memorias, Sexto Congreso Internacional sobre Formación de Profesores de Ciencias. 08 al 10 de octubre de 2014, Bogotá

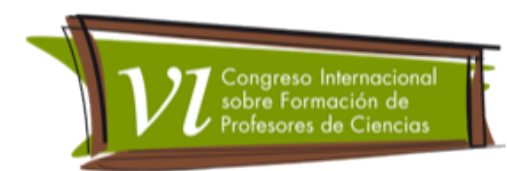

Luego de conocer las problemáticas de las instituciones, se pretende realizar una propuesta de diseño curricular basado en CSC O CSA para abordar las temáticas propuestas en los grados cuarto y quinto de la institución educativa. Se propondrá el diseño de un microcurrículo que cumple con los planteamientos tanto del Ministerio de Educación como de la institución y que se construya por medio de la interacción de la comunidad educativas.

\section{Resultados Esperados}

Para la construcción del diseño curricular, se realiza como primera medida un diagnóstico con los estudiantes de las instituciones, generando una lluvia de ideas desde la definición de las palabras "global", "local", "socioambiental", "sociocientífico", generando distintas opiniones en los estudiantes, donde ellos mismos comienzan a destacar algunas problemáticas locales-globales, dentro de ellas las más mencionadas fueron: la contaminación o mal uso del agua, contaminación por basuras, pérdida de valores y conflictos entre las personas, entre otras.

Teniendo en cuenta las opiniones de los estudiantes, la siguiente actividad a desarrollar consiste en presentar problemáticas globales y locales relacionadas con las temáticas planteadas por ellos, con el objetivo de identificar la cuestión sociocientífica o socioambiental a desarrollar.

Dentro de los resultados esperados luego de la construcción e implementación del microcurrículo, se destacan:

- Modificar la práctica docente por medio de la implementación de una propuesta innovadora que posibilite al docente la integración de distintos conocimientos en el desarrollo de las clases.

- Aumentar el interés y motivación de los estudiantes con respecto a las ciencias naturales.

- Favorecer la comprensión de las problemáticas locales-globales desde el desarrollo del microcurrículo.

\section{Conclusiones previas}

La construcción del microcurrículo enfocado en las cuestiones sociocientíficas o Socioambientales permitirá una renovación en el aula de clase, teniendo en cuenta que no cambiará solo el pensamiento de los estudiantes, también el de los docentes, generando actitudes y valores positivos hacia la ciencia. 
Revista Tecné, Episteme y Didaxis: TED. Año 2014, Número Extraordinario. ISSN Impreso: 0121-3814, ISSN web: 2323-0126

Memorias, Sexto Congreso Internacional sobre Formación de Profesores de Ciencias. 08 al 10 de octubre de 2014, Bogotá

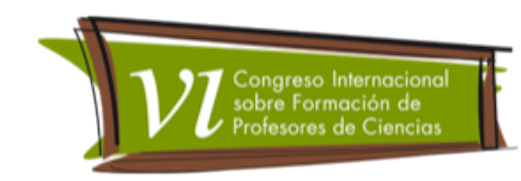

\section{Referencias Bibliográficas}

Ley 115 (1994).

Hernández, R., Fernández, C., \& Baptísta, P. (2006). Metodología de la investigación (Cuarta ed.). México: Mc Graw-Hill.

Martínez, L. F. (2012). Questões sociocientíficas na prática docente. Ideologia, autonomia e formação de professores. Esitora UNESP.

Martínez, L., Parga, D., \& Gómez, D. (2012). Cuestiones sociocientíficas en la Formación de Profesores de Ciencias. EDUCyT(Extraordinario), 139-151.

Membiela, P. (2002). Investigación - acción en el desarrollo de proyectos curriculares innovadores de ciencias. Educación en Ciencias, 20(3), 443-450.

Mora, W., \& Parga, D. (2010). La imagen pública de la química y su relación con la generación de actitudes hacia la química y su aprendizaje hacia la química y su aprendizaje. Tecné Epistemé y Didaxis: TED(27).

Ratcliffe, M. (2009). Human Rights and Citizenship Education. Eleventh Conference of the Children's Identity and Citizenship in Europe Academic Network.

Stenhouse, L. (1981). Investigación y Desarrollo del Currículum. Quinta Edición. Morata. Madrid.

Torres, N. (2011). Las Cuestiones Sociocientíficas: Una Alternativa de Educación para la Sostenibilidad. Luna Azul(32), 45-51. 